\title{
EFFECTS OF FREQUENCY ON THE AUDITORY PERCEPTION OF OPEN- VERSUS CLOSED-CLASS WORDS
}

\author{
Alette P. Haveman \\ Max-Planck-Institute for Psycholinguistics, \\ Nijmegen, The Netherlands
}

\begin{abstract}
Over the past couple of decades, it has been repeatedly investigated whether open-class items are processed in a different way from closed-class items. Most studies, however, have been bedeviled by difficulties in controlling all relevant distinctions between open- and closed-class items. For example, whereas openclass items have a relatively low frequency of occurrence, closedclass words have a very high frequency. The current study investigates auditory lexical decision on open- versus closed-class items when the effect of frequency is controlled for. Results revealed faster responses to high frequency open-class items when compared to closed-class items of similar frequency. Furthermore, responses to both low frequency open-class items and nonwords were significantly different from the responses to the high frequency open-class items, but not from responses to the high frequency closed-class items. Similar latencies for closed-class items and nonwords suggest that the open/closed-class distinction might be due to the clear lexical meaning of open-class items as opposed to the more grammatical function of closed-class words.
\end{abstract}

\section{INTRODUCTION}

The vocabularies of languages like English and Dutch fall into two classes: an open-class item set consisting of nouns, verbs, adjectives, and adverbs, and a closed-class item set that contains minor lexical categories like pronouns and articles. One of the most striking distinctions between open- and closed-class items is their different frequency of occurrence. In contrast to the low frequency of occurrence of most open-class items, closed-class items are used with a much higher frequency. Since word frequency effects are likely to influence lexical access (Gordon, 1985), these effects received a great deal of attention in research on possible processing differences between open- and closed-class items on an access and retrieval level. For example, based on the absence of a frequency effect for closed-class items in visual lexical decision, Bradley (1978) argued for a specialized lexical access routine for the retrieval of closed-class elements during speech processing. Later studies, however, did not succeed in replicating this result. Not only were frequency effects found for both open- and closed-class items with similar frequencies (Gordon \& Caramazza, 1982; Segui, Mehler, Frauenfelder, and Morton, 1982), both classes also showed a non-linear function of reaction time with log frequency (Gordon and Caramazza, 1985). The flattening of the frequency distribution in the higher ranges (higher than 400 occurrences per million or $2.5 \log$ frequency), though, turned out to be significant for the closed-class items only. This discrepancy between the two item groups was attributed to wordspecific influences on lexical decision speed in general. Although the open and closed class thus exhibited equal effects of frequency, Gordon and Caramazza (1985) showed that under masked conditions, responses to open-class items were somewhat faster than responses to closed-class items of comparable frequency. Gordon and Caramazza interpreted this result as evidence against the existence of a specialized processing routine for closed-class items, since they assumed that especially the closed-class items should benefit from such a routine. Taken together, the results of these studies seem to indicate that distinctions between open- and closed-class items do not manifest themselves at the level of lexical access and retrieval.

This conclusion seemed to be confirmed by findings presented by Matthei and Kean (1989), using auditory instead of visual lexical decision. With open- and closed-class items from different frequency ranges (mean log frequencies of 2.18 and 3.11, for the open- and closed-class items, respectively), Matthei and Kean found frequency-dependent reaction times in both lexical classes. However, no nonlinearities could be shown in their reaction time versus frequency analysis. For the lack of a frequency saturation effect for high frequency items, two possible explanations were given. First, strong effects of duration were found, which might have interacted with the effect of frequency. Second, the lack of a frequency saturation effect might have been due to the difference in the modality of presentation. Auditory presentation would then prevent floor effects from occurring. In addition to the frequency sensitivity of closed-class items, the results of Matthei and Kean showed similar reaction times for the open- and closed-class item sets (490 msec. and 507 msec., respectively). Given the considerably higher frequency of most of the closed-class items, however, faster reaction times for the closed-class item set would be expected. Furthermore, because of the different frequency ranges of the open- and closed-class items, it is fairly hard to disentangle the influence of frequency from other factors like meaning.

Using Dutch as a language that allows for a comparison between open- and closed-class items of similar frequency, the present study investigates auditory lexical decisions on open- versus closed-class words when the effect of frequency is controlled. The results will be discussed with respect to Gordon and Caramazza (1982; 1985). They suggested that faster responses to open-class items than to comparable closed-class items would not only argue against a specialized access routine for closed class items, it would also make it difficult to explain the frequency insensitivity of 
closed-class items as the trivial expression of a reaction-time floor effect. Although the open- and closed-class comparison is the primary interest of this study, low frequency open-class and nonword fillers will also be analyzed to investigate the possible role of semantics in the perception of open- versus closed-class words.

\section{METHODS}

\subsection{Subjects}

The twenty undergraduate students taking part in this experiment were drawn from the subject pool of the Max-Planck-Institute for Psycholinguistics. Three students were replaced by other students because of their extreme high error rates $(>40 \%)$. Most of these errors were due to responses that were given before item offset. The participants ( 15 females and 5 males) ranged in age between 20 and 35 years old, with a mean age of 25 . All students were native speakers of Dutch, and they were paid for their participation.

\subsection{Materials}

The target item set contained 12 monosyllabic high frequency open-class items and 12 monosyllabic high frequency (HF) closedclass words. Open-class items were either nouns, main verbs, or adjectives. The closed-class item set was composed of articles, conjunctions, pronouns, and quantifiers. The open- and closed-class items were matched as closely as possible for their initial phonemes and their number of phonemes (mean length of 3 phonemes). The items were furthermore matched for their lemma based frequency (the frequencies of all word forms from an inflectional paradigm are summed) according to the Dutch version of the CELEX lexical database. The frequency of the open-class items ranged from 11 to 2321 occurrences in a million, with a mean frequency of 719 (i.e., $2.86 \log$ frequency). The closed-class items covered a range from 16 to 2438 occurrences in a million (mean frequency of 683 ; i.e., $2.83 \log$ frequency).

An additional filler item set was selected, consisting of 24 low frequency (LF) open-class items and 48 legal nonwords. The openclass fillers were either nouns (12 items) or adjectives (12 items), varying in length from 3 to 5 phonemes. The mean lemma frequency of occurrence of the open-class fillers was 1 in a million. The nonwords were constructed by changing one phoneme of 24 randomly selected open-class words and 24 randomly selected closed-class words. In roughly half of the cases, the altered phoneme was in the beginning of the word, in the other half, the change was made in the end of the word.

\subsection{Presentation}

The items were presented in two blocks, each block consisting of $6 \mathrm{HF}$ open-class items and $6 \mathrm{HF}$ closed-class items intermixed with 12 filler LF open-class items and 24 filler nonwords. The order of the presentation of the blocks was counterbalanced across subjects, with the order of the individual items pseudo-randomized for every two participants. This randomization was restricted by four factors: 1) no more than three words or nonwords in succession, 2) no more than three successive experimental items, 3) no successive items with identical initial phonemes, and 4) the first four items of each block were filler items. A practice block of 14 items was also constructed. This block contained 7 randomly selected open- and closed-class items, and 7 legal nonwords.

\subsection{Procedure}

A list with both the words and the nonwords in random order was read by a trained female speaker of standard Dutch, and recorded in a sound attenuated booth using a SONY 670 DAT-recorder and a SENNHEISER HMD224 microphone.

Participants were tested either individually or in pairs, in sessions of about ten minutes. They were seated in a sound proof booth, and listened to the stimuli over headphones. A written instruction was given to listen to the items carefully, and decide whether an item was a word or a nonword after hearing the entire word. A button labeled "yes" had to pressed with their dominant hand where an item was judged to be a word. A button labeled "no" was used for the nonword responses. Participants were encouraged to respond as fast and accurately as possible. Subjects could respond to a presented word for $2000 \mathrm{msec}$., measured from the onset of this item. The next trial was presented after $660 \mathrm{msec}$.

Presentation of the practice items was followed by a short break in which the participants had an opportunity to ask questions. After this break, two blocks of experimental items were offered, separated from each other by a short pause.

\section{DATA ANALYSIS AND RESULTS}

Lexical decision response latencies were measured from the offset of the items. Responses were excluded from the analysis if: 1) the push-button response was given before the offset of an item or after the time-out period (4\% open-class responses, $11 \%$ closedclass responses), and 2) the push-button latency exceeded the mean RT per condition plus or minus $3 \mathrm{SD}(0.3 \%)$. The missing data and outliers were replaced by a value based on the mean of the item at hand plus the subject's mean RT deviation from the mean of the RTs of the other subjects.

\subsection{High Frequency Items}

The results showed significantly faster latencies for the HF openclass items (304 msec.) than for the HF closed-class items (407 msec.; $\mathrm{t}(19)=7.44$, two-tailed $\mathrm{p}<.01)$. In addition, significantly fewer errors were made in the open-class $(4 \%)$ versus the closedclass $(11 \%)$ item set $(\mathrm{t}(19)=2.94$, two-tailed $\mathrm{p}<.01)$. To assess whether these results are influenced by other factors, additional correlation analyses using Pearson correlation tests were carried out with the factors item frequency, item duration, uniqueness points (UPs), and cohort size. 


\subsubsection{Item Frequency}

Statistical examination of the frequency ranges with a t-test showed that the open- and closed-class item sets did not significantly differ in their lemma based frequencies. Furthermore, no significant correlation could be shown between the lemma based frequencies of the open- or the closed-class items and their corresponding decision latencies.

\subsubsection{Item Duration}

The duration analysis showed a minimal, non significant difference between the mean duration of the open-class items $(680 \mathrm{msec}$.) and the mean duration of the closed-class items $(683 \mathrm{msec}$.). These durations did not influence the decision latencies of either the open- or the closed-class item set.

\subsubsection{Uniqueness Point}

Another factor that might have influenced the decision latencies are the points at which the open- and closed-class items can be uniquely identified, i.e., their uniqueness point or UP. Examination of the UPs revealed no such difference between the two item sets. In fact, except for the closed-class word zulks (such a thing / this), none of the items could be uniquely identified at its offset.

\subsubsection{Cohort Size}

To compute the cohort size of an item, the longest possible word starting with this item was selected. Successively, the cohort of this word was determined on a phoneme basis (one phoneme equalled a vowel, a consonant, a long vowel, a diphthong, or an affricate) with use of the lemma lexicon of the CELEX database. For the open-class item set, a cohort size of 6042 words was found; the closed-class item set had a cohort of 5169 words.

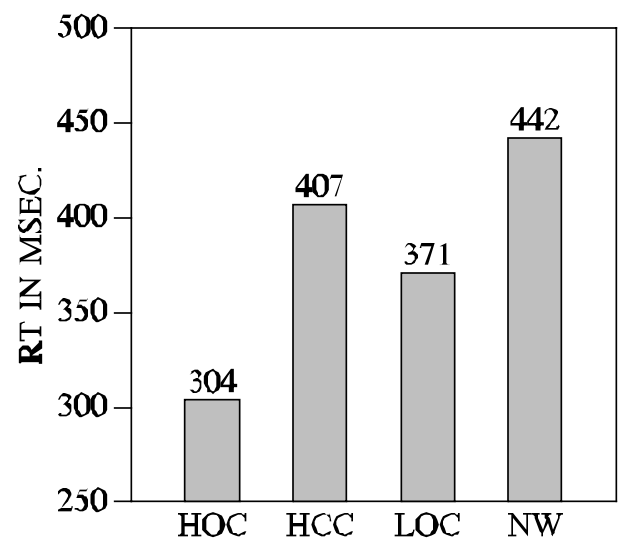

Figure 1: Mean decision latencies for the high frequency open(HOC) and closed-class (HCC) items, the low frequency open-class fillers (LOC), and the nonword fillers (NW).
The difference between the item sets did not reach the level of significance on a t-test. Although the mean frequency of the members of the closed-class cohorts was somewhat higher than the mean frequency of the members of the open-class cohorts (136 versus 110 , respectively), this difference did not turn out to be significant. Because of the shape of frequency distributions in general, the median frequencies of the open- (1.0) and closed-class (1.2) item set were also determined. Again, a t-test did not show any significant difference. Finally, the decision latencies of both the open- and the closed-class items did not correlate with either the absolute cohort size or with the cohort size corrected for frequency.

\subsection{Low Frequency Items And Nonwords}

In addition to the HF open- and closed-class items, a filler set of LF open-class items and of nonwords was used. Although these filler items were not matched with the experimental items for their number of phonemes, a post-hoc analysis was carried out to assess possible differences between HF and LF open-class items relative to HF closed-class items and nonwords.

A mean decision latency of $371 \mathrm{msec}$. was found for the LF openclass items, and the non-words had a mean latency of $442 \mathrm{msec}$. A Newman-Keuls analysis showed that both latencies differed significantly from the mean latency of the HF open-class items (df $=57, \mathrm{MSe}=3306, \mathrm{p}<.01)$. However, the latencies of the HF closed-class items did not differ from the decision latencies of either the LF open-class fillers or the nonwords. The mean latencies of both the target and the filler items are presented in Figure 1.

Analysis of the errors showed $18 \%$ errors in the LF open-class items and 6\% errors in the nonwords. In Figure 2, the error scores of the filler items are presented together with the error scores of the target items.

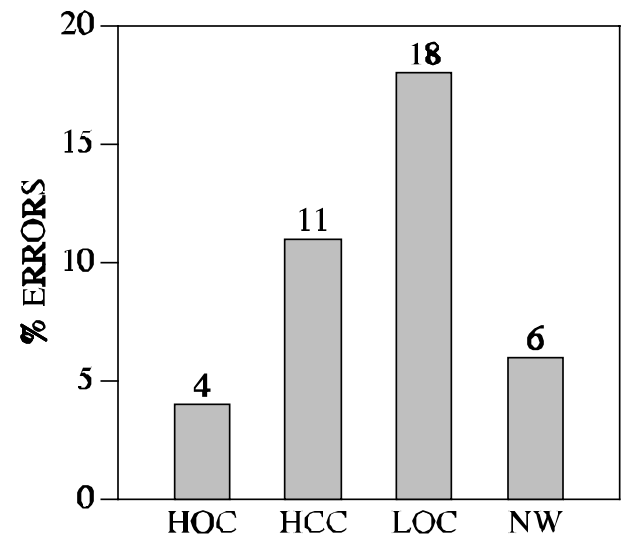

Figure 2: Percentages of errors made in the high frequency open(HOC) and closed-class (HCC) items, the low frequency open-class fillers (LOC), and the nonword fillers (NW). 


\section{DISCUSSION AND CONCLUSION}

The primary goal of the present paper was to compare auditory lexical decision responses to open- versus closed-class words of similar frequency. Results revealed faster reaction times for the high frequency open-class items than for the high frequency closed-class items, independent of item durations, uniqueness points, and cohort sizes. Furthermore, subjects tended to make fewer errors in the open-class items when compared to the closedclass items. These findings confirm earlier results obtained with a visual paradigm where open- and closed-class items were presented under masked conditions. One might wonder, however, whether slow reaction times for the closed-class vocabulary words indeed argue against a special retrieval mechanism for these items as proposed by Gordon and Caramazza (1985). Since closed-class items mainly indicate grammatical relationships between open-class words, closed-class items cannot serve their normal function when presented in isolation. Open-class items, on the other hand, have a clear lexical meaning, both when presented in running speech and in isolation. This difference between the two vocabulary types does, in fact, predict an advantage for the recognition of openversus closed-class items in a lexical decision task, since word recognition in such a task is based on the meaning of the items. The difference in responses found for open- and closed-class items of similar high frequency, however, does indicate that one cannot simply state that high frequency closed-class items show frequency insensitivity as a result of a reaction time floor effect. The analysis of the relationship between reaction times and frequencies of occurrences in the current study showed that neither the open- nor the closed-class latencies correlated with their frequency of occurrence. This result again confirms findings from visual lexical decision. Therefore, the absence of a frequency saturation effect in Matthei and Kean's (1989) auditory lexical decision study is not likely to be caused by the different modality that was used.

How can the slower responses to the closed-class items be explained? In previous lexical decision studies on open- and closed-class distinctions, only responses to the real words have been analyzed. However, since open- and closed-class items differ in the amount of meaning they convey (open-class items have an obvious lexical meaning, closed-class items tend to indicate the grammatical relations between open-class items), a comparison with items having no or little lexical meaning could possibly shed some light on the cause of the obtained result. Whereas high frequency open-class words showed different responses from both low frequency open-class words and nonwords, high frequency closed-class words did not differ from either low frequency openclass words or nonwords. This suggests that the open/closed-class distinction is indeed due to the difference in lexical meaning between the two vocabulary classes.

It has been argued, however, that the composition of word lists might have large influences on lexical decision latencies (Kolk and Blomert, 1985). If only a small number of closed-class items is used, the listener will be biased towards a nonword response because closed-class items become "nonword-like". In the present experiment, however, the largest proportion of the items had a low semantic content (i.e., nonwords, closed-class items, and low frequency open-class items). It seems, therefore, unlikely that the current findings were caused by the composition of the materials that were used.

To conclude, the present auditory lexical decision study shows that when open- and closed-class items have a similar frequency and are therefore equally familiar to listeners, closed-class items are harder to recognize. In fact, high frequency closed-class items are processed in a similar way to very low frequency open-class items or nonwords. These results suggest that the open/closed-class distinction might be due to the clear lexical meaning of open-class items as opposed to the more grammatical function of closed-class items.

\section{REFERENCES}

1. Bradley, D.C., Computational distinctions in vocabulary type. Unpublished doctoral dissertation, MIT, Cambridge, MA., 1978.

2. Gordon, B. "Subjective frequency and the lexical decision latency function: Implications for mechanisms of lexical access", Journal of Memory and Language 24, 631-645, 1985.

3. Gordon, B., and Caramazza, A. "Lexical decisions for open and closed class words: Failure to replicate differential frequency sensitivity", Brain and Language 15, 143-160, 1982.

4. Gordon, B., and Caramazza, A. "Lexical access and frequency sensitivity: Frequency saturation and open/closed class equivalence", Cognition 16, 99-120, 1985.

5. Kolk, H.H.J., and Blomert, L. "On the Bradley hypothesis concerning agrammatism: The nonword interference effect. Brain and Language 26, 94-105, 1985.

6. Matthei, E.H., and Kean, M.-L. "Postaccess processes in the open vs. closed class distinction", Brain and Language 36, 163-180, 1989.

7. Segui, J., Mehler, J., Frauenfelder, U., and Morton, J. "The word frequency effect and lexical access", Neuropsychologia 20, 615-627, 1982.

Special thanks go to Anne Cutler for her helpful comments on previous versions of this paper.

Address correspondence to: Alette Haveman, Max-Planck-Institute for Psycholinguistics, Wundtlaan 1, 6525 XD Nijmegen, The Netherlands. E-mail: alette.haveman@mpi.nl 